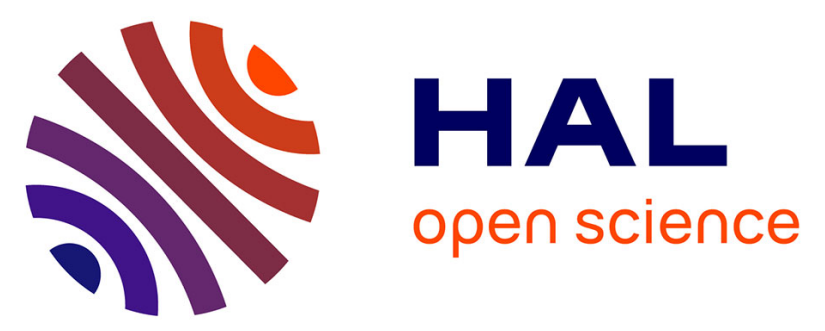

\title{
An optimization method with experimental validation for the design of extrusion wire coating dies for a range of different materials and operating conditions
}

\author{
N. Lebaal, S. Puissant, Fabrice Schmidt, D. Schlaefli
}

\section{- To cite this version:}

N. Lebaal, S. Puissant, Fabrice Schmidt, D. Schlaefli. An optimization method with experimental validation for the design of extrusion wire coating dies for a range of different materials and operating conditions. Polymer Engineering and Science, 2012, 52 (12), pp.2675-2687. 10.1002/pen.23203 . hal-01687329

\author{
HAL Id: hal-01687329 \\ https://hal.science/hal-01687329
}

Submitted on 15 Feb 2019

HAL is a multi-disciplinary open access archive for the deposit and dissemination of scientific research documents, whether they are published or not. The documents may come from teaching and research institutions in France or abroad, or from public or private research centers.
L'archive ouverte pluridisciplinaire HAL, est destinée au dépôt et à la diffusion de documents scientifiques de niveau recherche, publiés ou non, émanant des établissements d'enseignement et de recherche français ou étrangers, des laboratoires publics ou privés. 


\title{
An Optimization Method with Experimental Validation for the Design of Extrusion Wire Coating Dies for a Range of Different Materials and Operating Conditions
}

\author{
N. Lebaal, ${ }^{1}$ S. Puissant, ${ }^{2}$ F.M. Schmidt ${ }^{3}$ D. Schläfli ${ }^{4}$ \\ ${ }^{1}$ Mechatronics Methods Models and Skills Laboratory (M3M), Research Institute on Transportation, \\ Energy and Society (IRTES), Université de Technologie de Belfort-Montbéliard, Belfort cedex, 90010 France \\ ${ }^{2}$ Brugg Cables Industry AG, Klosterzelgstrasse 28, CH-5201 Brugg, Switzerland \\ ${ }^{3}$ Université de Toulouse, ICA (Institut Clément ADER), Mines Albi, Ecole des Mines Albi, Campus Jarlard \\ 81013 Albi Cedex 9, France
}

${ }^{4}$ Maillefer Extrusion SA Route du bois 37, 1024 Ecublens, Switzerland

\begin{abstract}
The objective of this article is to determine a wire coating-hanger melt distributor geometry to ensure a homogenous exit velocity distribution that will best accommodate a wide material range and multiple operating conditions (i.e., die wall temperature and flow rate change). The computational approach incorporates finite element (FE) analysis to evaluate the performance of a die design and includes a nonlinear constrained optimization algorithm based on the Kriging interpolation and sequential quadratic programming algorithm to update the die geometry. Two optimization problems are then solved, and the best solution is taken into account to manufacture the optimal distributor. The Taguchi method is used to investigate the effect of the operating conditions, i.e., melt and die wall temperature, flow rate and material change, on the velocity distribution for the optimal die. In the example chosen, the wire coating die geometry is optimized by taking into account the geometrical limitations imposed by the tool geometry. Finally, the FE analysis and optimization results are validated by comparison with the experimental data obtained with the optimal die. The purpose of the experiments described below is to investigate the effect of material change.
\end{abstract}

\section{INTRODUCTION}

The coat-hanger melt distributor (Fig. 1) is commonly used in the wire coating process. Its task is to distribute

Correspondence to: Nadhir Lebaal; e-mail: nadhir.lebaal@utbm.fr the melt around the conductor uniformly. Balancing the distribution of flow through a die to achieve a uniform velocity distribution across the die exit is one of the most difficult tasks of extrusion die design.

For the polymer extrusion industry, the most challenging and demanding work is to explore how to reduce or even eliminate die correction. In general, increasing the length of the die-land results in a significant flow resistance, the effect of which is to improve the final melt distribution. However, this increase in land length may rapidly lead to an excessive increase of the pressure drop across the die. A choker bar profile can also be optimized [1] to obtain a uniform velocity at the die exit. But the use of this choker bar also leads to an increase of the pressure drop across the die which may lead to a die body deflection. Therefore, the channel geometry (manifold) of a coat hanger die should be optimized in such a way that a uniform velocity distribution at the die exit is obtained without excessively increasing the pressure drop across the die.

The design of polymer extrusion dies is complicated by the nonlinear relationship between the resin viscosity and shear rate. The distribution of flow through a die, which enables a uniform velocity to be achieved, is a function of the total throughput, and therefore a function of the shear thinning and the heat dissipation of the resin. Computer simulation of the extrusion process must take into account the nonlinear material behavior of the polymer and accurately predict the pressure and temperature distributions within the die.

The performance of extrusion dies depends, amongst other things, on the design of the flow channel and on the operating conditions adopted during extrusion [2, 3]. This 


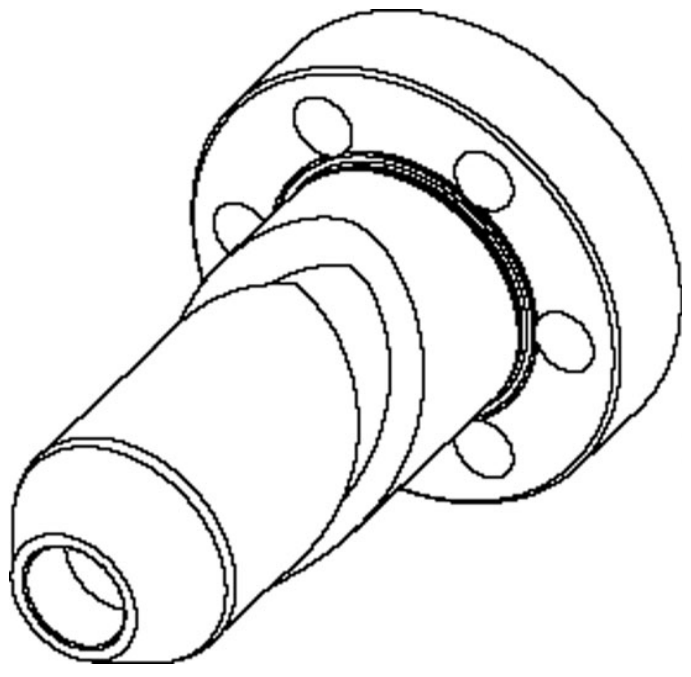

FIG. 1. Coat-hanger melt distributor.

may lead to problems with materials that have very different rheological properties compared to the design material, with the performance degrading to an unacceptable level. Chen et al. [4] showed, using a Taguchi method, that the operating conditions, the material change and the die geometry have a great influence on the velocity distribution at the die exit. Wang [5] investigated the effect of manifold angle and the contour of the manifold cross-section on the flow distribution in the coat-hanger die using three-dimensional finite element (FE) software with the assumptions of isothermal flow and power law fluids. Design of experiment was also used to study the effect of process parameters in polymer extrusion by Younes et al. [6]. They used a statistical approach using a factorial design of experiment to provide the description of rheological mechanisms through mathematical interactions, and study the effect of the polymer melt flow index and extrusion temperature on the crystallographic shape and size [7]. Carneiro et al. [8] have studied for a rectangular polypropylene profile the effect of different extrusion conditions. Taguchi design of experiments is used to identify the most relevant processing variables. They have concluded that the most significant processing variable determining the mechanical properties of the extrusion profiles is the extrusion temperature. The effect of process parameters of extrusion of aluminium on the flow balance and temperature evolution of the extruded sections have been studied by Bastani et al. [9]. The authors minimized the radial variation of exit velocity and exit temperature in a 2D model by means of selecting the appropriate combination of process parameters and concluded that minimizing the exit temperature and velocity can result in a decrease in the homogeneity of temperature and speed in the crosssection of the produced part.

The diversity in the rheology of different polymers also needs individual optimization of the die for each polymer. The combination of polymer and die channel geometry often requires additional equipment such as a choker bar [10]. In this case, a trial-and-error approach can be used to obtain a uniform velocity at the die exit. This complexity of the polymer rheology further increases the difficulty of the die optimization problem. If the polymer rheology is not taken into account accurately while optimizing the die, the predicted velocity, pressure and temperature fields are expected to have large errors, which may result in a nonoptimal die design.

Nevertheless, it is theoretically possible to design dies where the flow distribution is independent of flow properties and in particular, independent of the degree of shear thinning. Winter and Fritz [11], presented a theory for the design of coat-hanger dies, with circular or rectangular section distribution manifolds. For a given aspect ratio (height/width) of the manifold, the theory predicts material independence of the flow distribution. However, Lebaal et al. [12] showed using three-dimensional simulation software, and experimental validation, that the distribution obtained by this method may not be optimal in practice.

Smith [13] optimized a flat die design to operate well at multiple temperatures. The author shows that the exit velocity distribution is influenced by the melt temperature. In fact, the power law rheological model parameters of the material are varying according to the melt temperature. To simplify the optimization method, the lubrication approximations are used to model isothermal flow of power-law fluids.

The majority of the optimization algorithms used requires a great number of simulations, increasing by this fact the computing time. This means that, for complex geometries, the computational resources and time required for analysis of extrusion dies are considerable. To prevent or at least to minimize this drawback, Shahreza et al. [14] presented an interesting optimization procedure to achieve a uniform outlet flow of molten polymer for a profile die with various thicknesses in die outlet cross section. The die exit velocity is based on the results of $3 \mathrm{D}$ flow simulation. A design sensitivity analysis using the direct differentiation method can be easily included into a FE code to calculate the gradient of objective functions. For this purpose Sienz et al. [15] proposed a procedure using a design sensitivity analysis to optimize a profile extrusion dies. Nóbrega et al. [16] propose to optimize the flow channel of profile extrusion die, a die design code based on the finite volume methodology and two optimization algorithms (SIMPLEX and heuristic method). Two optimization strategies are proposed, the first one is based on the length control and the second one is based on the thickness. The authors conclude that the extrusion dies optimized on the basis of length control have a higher sensitivity to processing conditions compared to those optimized on the basis of thickness. Meta model optimization strategies were presented recently for die design in the polymer extrusion process, $\mathrm{Mu}$ et al. [17], proposed an optimization strategies based on back-propagation neural network, and the nondominated sorting genetic algorithm II (NSGA-II) to optimize the extrusion die. The NSGA-II is performed for the search of globally optimal design variables with its objective functions evaluated by 


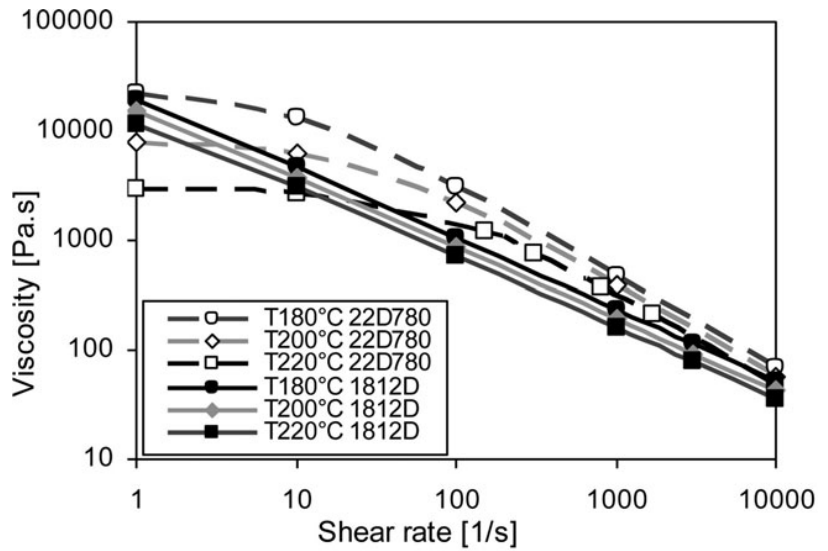

FIG. 2. Viscosity of LDPE (22D780 and Lupolen 1812D) "Carreau \&Arrhenius law."

the established neural network model. The Mode FRONTIER software for the optimization algorithm is coupled with a FE simulation to ensure the dimensional precision of the final products. For this purpose the velocity relative difference and the swell ratio are taken as objectives functions. This optimization tool (Mode FRONTIER) is interesting and easy to use in other polymer processing such as the optimization of performance of injection molding machine [18].

In this work, a robust and an effective optimization method has been developed for the wire coating processes, and tested using various strategies. This method consists of an optimization routine coupled with geometry and mesh generators and 3D computational software $\left(\right.$ Rem3D ${ }^{R}$ ) based on the FE method, to simulate a nonisothermal polymeric flow.

The optimization model was established according to the flow balance principle where the outlet flow distribution uniformity was taken as an objective function, the maximum pressure in the die gave the constrained function, and the die structure parameters were the design variables. The FEM simulation is able to predict, within acceptable computation times, the velocity, pressure, shear field and temperature distribution. The results were adopted for the calculation of the objective and constrained functions. The sequential quadratic programming (SQP) algorithm was used to solve a nonlinear constrained optimization problem and the search of optimal design variables. The above optimization approach is applied to achieve the optimal design of a wire coat hanger die geometry which enables a good performance with a wide range of materials and multiple operating conditions. The experimental results presented show that it is feasible and reasonable.

\section{MODELING AND SIMULATION}

The extrusion simulation is carried out using the 3D computation software by FEs REM3D ${ }^{\circledR}$. The flow equa- tions are derived from the Navier-Stokes incompressible equations. A mixed FE method for incompressible viscous flow is used. The flow solver uses tetrahedral elements with a linear continuous interpolation of both the pressure and the velocity and a bubble enrichment of velocity. The mass, momentum, and energy conservation equations, are used to follow the material behavior, from which the velocity, pressure, and temperature fields are determined.

$$
\left\{\begin{array}{c}
\nabla \cdot(2 \eta(\dot{\gamma}) \dot{\varepsilon}(v))-\nabla p=0 \\
\nabla \cdot \vec{v}=0 \\
\rho \hat{c} \frac{d T}{d t}=-\nabla \cdot q+\sigma: \dot{\varepsilon}(v)
\end{array}\right.
$$

The behaviors laws used give a relationship for the viscosity versus the shear rate and temperature. According to Winter and Fritz [11], Schläfli [19], and Smith [13], the exit velocity distribution of real distributors depends on the slope (power law index) of the viscosity-strain rate curve. This makes the exit velocity distribution sensitive to the material and flow change. To analyze the effect of material change on the distribution result, two different polymers are selected (Fig. 2). A low density polyethylene (LDPE) referenced LDPE 22D780, is used because of its rheological behavior. It is noted that the width of the transition region between Newtonian (constant viscosity) and the power-law (linear) region is important. A second material referenced Lupolen 1812D, is selected. In this case, the log-log-viscosity curves are linear (almost no Newtonian or constant viscosity part) and the temperature dependence of the viscosity is relatively small.

A Carreau-Yasuda/Arrhenius viscosity model is used to characterize the temperature $(T)$ and shear rate $(\dot{\gamma})$ dependence of viscosity:

$$
\eta=\eta_{\infty}+\left(\eta_{0}(T)-\eta_{\infty}\right)\left[1+\left(\eta_{0}(T) \frac{\dot{\gamma}}{\tau_{\mathrm{s}}}\right)^{a}\right]^{\frac{m-1}{a}}
$$

with

$$
\eta_{0}(T)=\eta_{0}\left(T_{\text {ref }}\right) \exp \left[\beta\left(\frac{1}{T}-\frac{1}{T_{\text {ref }}}\right)\right]
$$

where $\eta_{0}, \beta, T_{\text {ref }}, a, \eta_{\infty}$, and $m$ are material parameters. The rheological properties of the two polymers (Table 1) are obtained from the data bases of REM3D ${ }^{\mathbb{R}}$ commercial software $\left(\mathrm{MatDB}^{\circledR}\right)$. Two other thermoplastic materials selected for the experiments, were linear low density polyethylene (LLDPE “LLN 1004 YB”); and poly (vinyl chloride) (poly(vinyl chloride), PVC “FKS 910 R”).

TABLE 1. Rheological parameter of LDPE $22 D 780$ and Lupolen $1812 D$.

\begin{tabular}{lrcrcr}
\hline Materials & $\eta_{0}\left[\mathrm{~Pa} . \mathrm{s}^{\mathrm{m}}\right]$ & $m$ & $\tau_{\mathrm{s}}[\mathrm{Pa}]$ & $T_{\text {ref }}[\mathrm{K}]$ & $\beta[\mathrm{K}]$ \\
\hline LDPE 22D780 & 8314 & 0.159 & 224062 & 473 & 11703 \\
Lupolen $1812 D$ & 43434 & 0.347 & 10555 & 473 & 6156 \\
\hline
\end{tabular}




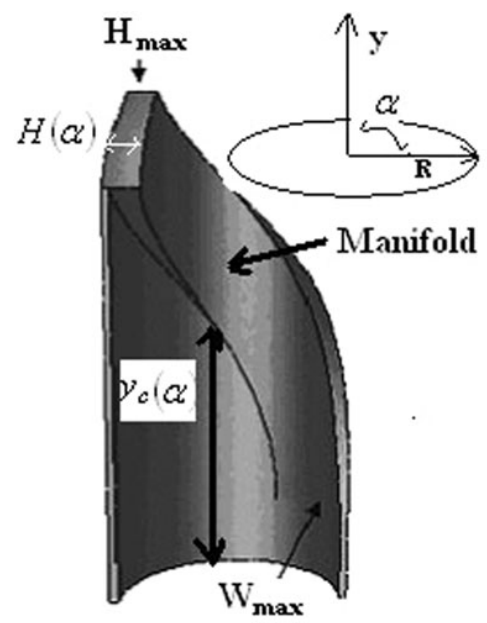

a)

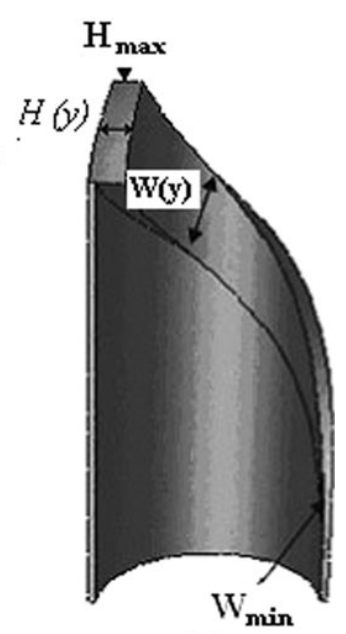

b)
FIG. 3. Coat-hanger distribution system. (a) and optimization variables $W(y), H(\alpha)$ (a) and $W(y), H(y)(b)$.

By symmetry, only one half die is modeled for a flow of $120 \mathrm{~kg} / \mathrm{h}$. This corresponds to a volume flow of $34,400 \mathrm{~mm}^{3} /$ $\mathrm{s}$. The entrance melt temperature $\left(T_{\mathrm{m}}\right)$ and wall die temperature $\left(T_{\mathrm{f}}\right)$ are $T_{\mathrm{m}}=180^{\circ} \mathrm{C}$ and $T_{\mathrm{f}}=185^{\circ} \mathrm{C}$, respectively.

\section{OPTIMIZATION STRATEGY}

This section describes the coat hanger melt distributor design problem. First, the design variables and the parameterization of the die manifold is explained and then the objective and constrained functions used in the optimization problem are defined. Finally, the optimization procedure is illustrated.

The optimization method used in this work is based on the Kriging interpolation and SQP algorithm. The Kriging consists in the construction of an approximate expression of objective and constrained functions using evaluation points starting from a composite design of the experiment [20]. Then, the approximated problem is solved using the SQP algorithm to obtain the optimal solution.

\section{Die Design Variables}

For a given die diameter $(2 \mathrm{R})$, a slit height $(h)$, and an initial manifold of constant width $(W)$ (Fig. 3), the manifold thickness $H(\alpha)$ and the contour lines $y_{\mathrm{c}}(\alpha)$ can be calculated by the mean of the analytical model presented by Winter and Fritz [10] as follows:

$$
\begin{gathered}
H(\alpha)=h \sqrt{R \cdot(\pi-\alpha) / W} \\
y_{\mathrm{c}}(\alpha)=2 W \sqrt{R \cdot(\pi-\alpha) / W-1}
\end{gathered}
$$

Lebaal et al. [12] already showed the limitations of this analytical model. However the authors [12] note, that, for a geometry obtained using this model, the material has a weak influence on the exit velocity distribution.
Within this work, we want to obtain some die geometries that will be machined afterward. Indeed, they are very often subject to geometrical requirements related to the manufacturing process. Within this framework, during the optimization procedure, several geometrical constraints dependent on the manufacturing process and to the tool geometry are applied.

In our case, these geometrical requirements imposed by the machine tools are: the tool cutting edge radius (RF) and diameter (D). The manifold will be milled by a tool of diameter $8 \mathrm{~mm}$. This implies that the minimal manifold width $W_{\min }$ should not be lower than $8 \mathrm{~mm}$. The second requirement is the tool cutting edge radius $\mathrm{RF}=3$ $\mathrm{mm}$, which will be taken into account during the milling of the part geometry.

Also, other geometrical limitations related to the tooling, which must be adapted to the optimal die. To achieve this goal, several geometrical constrained must be imposed (Fig. 4). The width of entry $W_{\text {entry }}$ must be equal to $20 \mathrm{~mm}$; the maximum length $(y)$ of the manifold should not exceed $85 \mathrm{~mm}$. The overall length of the die is $95 \mathrm{~mm}$. The overall length of the flow before the flux separator is of $112.5 \mathrm{~mm}$. To obtain a length of the manifold which does not exceed the imposed length of 85 $\mathrm{mm}$, the manifold contour lines is calculated for a constant width of $W=10 \mathrm{~mm}$.

For a diameter of $55 \mathrm{~mm}$, a slit height of $3 \mathrm{~mm}$ and an initial manifold of constant width, the contour lines $y_{\mathrm{c}}(\alpha)$ and the thickness variation $H(\alpha)$ of the manifold are calculated starting from Eqs. 4 and 5.

During the optimization procedure, the external contour lines of the die (determined by the initial parameters) remain constant. Consequently, two variables will be optimized to ensure better exit velocity distribution: manifold thickness and manifold width variation (Fig. 3).

Two cases are proposed to optimize the wire coat hanger melt distributor. In the first (case 1) the manifold thickness is varying linearly along the die circumference $H(\alpha)$ :

$$
H_{i}(\alpha)=c_{0}\left(R \alpha_{i}\right)+c_{1} \quad \forall \alpha \in\left[\begin{array}{ll}
0 & \pi
\end{array}\right]
$$

The constants $c_{0}, c_{1}$ are determined by the following boundary conditions:

$$
\left\{\begin{array}{l}
H(0)=H_{\mathrm{k}} \\
H(\alpha)=h
\end{array}\right.
$$

In the second (case 2), $H$ varies linearly along the length of the die $(H(y))$ as follows:

$$
\left\{\begin{array}{l}
H\left(y_{\max }\right)=H_{\mathrm{k}} \\
H(0)=h
\end{array}\right.
$$

with: $h$ being the slit die and $H_{\mathrm{k}}$ the manifold thickness at the die entrance. This second variable can vary during the optimization procedure as follows: $5 \leq H_{\mathrm{k}} \leq 15 \mathrm{~mm}$. 

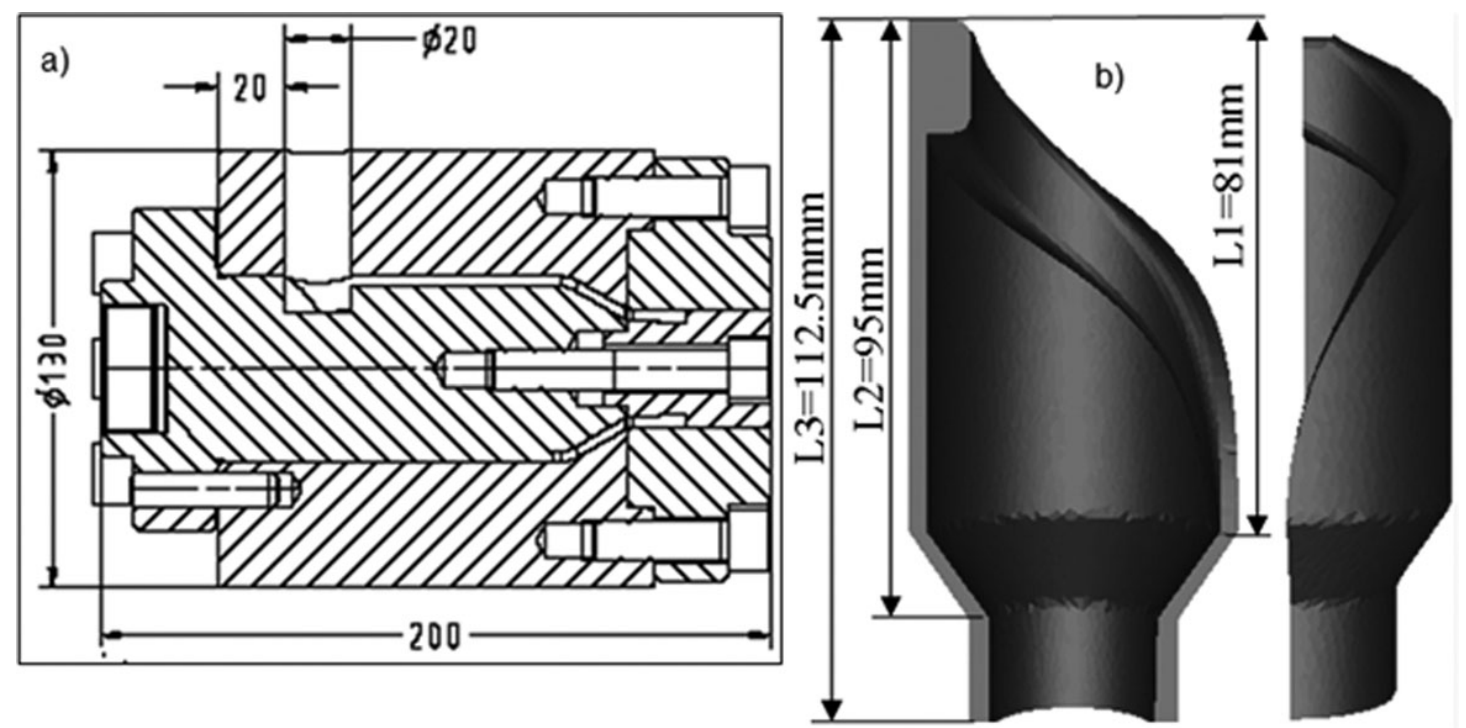

FIG. 4. Sketch of extrusion tool (a) and coat-hanger distribution system (b).

For the two cases, during the optimization procedure, the manifold width (variable $W$ ) varies linearly according to the die length $(y)$. The entrance manifold width must be equal to $W_{\text {entry }}=20 \mathrm{~mm}$ and at the exit it should not be lower than the tool machining diameter. The latter parameter can vary during the optimization procedure and is limited by $8 \leq W_{\mathrm{k}} \leq 20 \mathrm{~mm}$.

$$
W(y)=\hat{P}(y) a
$$

where $\hat{P}=\left[\begin{array}{ll}1 & y\end{array}\right]$ is the polynomial basis function, and $a=\left\{\begin{array}{l}a_{0} \\ a_{1}\end{array}\right\}$ are the unknown coefficients that are determined by the boundary conditions:

$$
\left\{\begin{array}{l}
W\left(y_{\max }\right)=W_{\text {entry }} \\
W(0)=W_{\mathrm{k}}
\end{array}\right.
$$

One important need is to have a design process which is less dependent on personal experience. To automate the optimization procedure and to save time, a die design code has been developed in MATLAB ${ }^{\circledR}$. This code carries out the automatic search for the flow channel geometry and allowing the CAD to be processed and the die geometry to be changed automatically. From Eqs. 4 and 5, the manifold contour line is obtained. Then, with the optimization variables, the manifold thickness and width variations independently of the external contour line are obtained. From the manifold contour line, width and thickness, a three-dimensional mesh of the coat hanger melt distributor is generated.

\section{Objective and Constrained Functions}

Since the primary function of the wire coat-hanger melt distributor is to produce a uniform flow distribution across the die, this also means to achieve the minimum velocity dispersion $(E(x))$. The objective function is a positive exit flow uniformity index that becomes zero for perfect uniformity. Other considerations include the limitation of pressure to the one obtained by the initial geometry; this condition is translated by a constrained function $(g(x))$.

The optimization problem is defined as follows:

$$
\left\{\begin{array}{l}
\min \quad J(x)=\frac{E(x)}{E_{0}} \\
\text { Such that } g(x)=\frac{P(x)-\left(P_{0}\right)}{\left(P_{0}\right)} \leq 0
\end{array}\right\}
$$

where $(J(x))$ being the normalized objective function, is function of the vector of design variables $(x)$ and is obtained with the help of the velocity dispersion $(E(x))$, defined as follows:

$$
E(x)=\left(\frac{1}{N} \sum\left(\frac{\left|v_{i}(x)-\bar{v}(x)\right|}{\bar{v}(x)}\right)\right)
$$

and $E_{0}$ and $P_{0}$ are respectively the velocity dispersion (dimensionless velocity uniformity index) and the pressure in the initial die, which is given by the initial optimization parameters (Table 2), $N$ the total number of nodes at the die exit in the middle plane, $v_{i}$ the velocity at an exit node, and $\bar{v}$ the average exit velocity defined as:

$$
\bar{v}(x)=\frac{1}{N} \sum_{i=1}^{N} v_{i}(x)
$$

The constrained function $(g(x))$ is selected in a way to be negative if the pressure is lower than the pressure obtained by the initial die design (the pressure must be lower than the initial pressure). 
TABLE 2. Summary of the optimization results.

\begin{tabular}{lcc}
\hline \multicolumn{1}{c}{ Optimization results } & Initial & Case $1 W, H(x)$ \\
\hline CPU time & & $18 \mathrm{~h} 40$ \\
Iterations & 0 & 3 \\
Objective function $f$ & 1 & $18 \mathrm{~h} 16$ \\
Improvement of the velocity distribution $[\%]$ & 3 & 0.134 \\
Constraint function P/P0 & - & 87 \\
Global relative deviation $E[\%]$ & 1 & 0.92 \\
Global relative deviation of the average velocities $E_{g}^{s}$ & 19.77 & 2.65 \\
Variable $W[\mathrm{~mm}]$ & 115.25 & 20.97 \\
Variable $H[\mathrm{~mm}]$ & 7 & 14.68 \\
\end{tabular}

\section{Optimization Procedure}

To find the global optimum parameters with the lowest cost and a good accuracy, the Kriging interpolation, described in the next section, is adopted and coupled with SQP algorithm. The Kriging interpolation consists in the construction of an approximate expression of the objective and constraint functions (Eq. 11), starting from a limited number of evaluations of the real function. In this method, the approximation is computed by using the 15 evaluation points obtained by composite design of experiments.

The SQP algorithm is used to obtain the optimal approximated solution which respects the imposed nonlinear constraints. Since the successive evaluations of the approximated functions does not take much computing time, once the approximated objective and constraint functions are built, and to avoid falling into a local optimum, an automatic procedure is used which allows to resolving the optimization problem using SQP algorithms, starting from each point of the experimental design. Then, the best approximated solution among those obtained by the various optimizations is taken into account.

After that, successive local approximations are built, in the vicinity of the optima by taking into account the weight function of Gaussian type, the aim of the weight function is to slightly change the interpolations and makes the approximations more accurate locally, around the best optimum. The iterative procedure stops when the successive optimum of the approximated function are superposed with a tolerance $\varepsilon=10^{-6}$. Finally, another evaluation is carried out to obtain the real response in the optimization iteration.

An adaptive strategy of the search space is applied to allow the location of the global optimum. During the progression of the procedure, the region of interest moves and zooms by reducing the search space by $1 / 3$ on each optimum. In addition, an enrichment of the interpolation is made by recovering responses already calculated, and which are located in the new search space. The iterative procedure is stops when the successive points are superposed with a tolerance $\varepsilon=10^{-3}$.

\section{Kriging Interpolation}

The Kriging interpolation is used in many works [21, $22]$, to approximate a complexes function effectively.
This method is applied in this work to approximate the objective and constraint functions in an explicit form, according to the optimization variables. The approximated relationship of the objective and constraint function can be expressed as follows:

$$
\tilde{J}(x)=p^{T}(x) a+Z(x)
$$

with, $p(x)=\left[p_{1}(x), \ldots, p_{m}(x)\right]^{T}$, where $m$ denotes the number of the basis function in regression model, $a=$ $\left[a_{1}, \ldots, a_{m}\right]^{T}$ is the coefficient vector the $x$ is the design variables, $\tilde{J}(x)$ is the unknown objective or constraint interpolate function, and $Z(x)$ is the random fluctuation. The term $p^{T}(x) a$ in Eq. 14 indicates a global model of the design space, which is similar to the polynomial model in a moving least squares approximation. The second part in Eq. 14 is a correction of the global model. It is used to model the deviation from $p^{T}(x) a$ so that the whole model interpolates response data from the function.

The output responses from the function are given as:

$$
F(x)=\left\{f_{1}(x), f_{2}(x), \ldots f_{n}(x)\right\}
$$

From these outputs the unknown parameters $a$ can be estimated:

$$
a=\left(P^{T} R^{-1} P\right)^{-1} P^{T} R^{-1} F
$$

where $P$ is a vector including the value of $p(x)$ evaluated at each of the design variables and $R$ is the correlation matrix, which is composed of the correlation function evaluated at each possible combination of the points of design:

$$
\begin{aligned}
R= & {\left[\begin{array}{ccc}
R\left(x_{1}, x_{1}\right) & \cdots & R\left(x_{1}, x_{n}\right) \\
\vdots & \ddots & \vdots \\
R\left(x_{n}, x_{1}\right) & \cdots & R\left(x_{n}, x_{n}\right)
\end{array}\right] } \\
& +\left[\begin{array}{cccc}
w\left(x-x_{1}\right) & 0 & \cdots & 0 \\
0 & w\left(x-x_{2}\right) & \cdots & 0 \\
\vdots & \vdots & \vdots & \vdots \\
0 & 0 & \cdots & w\left(x-x_{n}\right)
\end{array}\right]
\end{aligned}
$$




$$
R_{i j}=\left(\left|x_{i}-x_{j}\right|^{2} * \ln \left|x_{i}-x_{j}\right|\right)
$$

A Gaussian type weight function with a circular support is adopted for the Kriging interpolation expressed as follows:

$$
w_{i}(x)=\left\{\begin{array}{cl}
\left(1-\frac{e^{-\left(d_{i} / c\right)^{2}}-e^{-\left(r_{w} / c\right)^{2}}}{1-e^{-\left(r_{w} / c\right)^{2}}}\right) & \text { if } d_{i} \leq r_{w} \\
1 & \text { if } d_{i} \geq r_{w}
\end{array}\right.
$$

where $d_{i}=\sqrt{\sum_{J=1}^{n}\left(x^{J}-x^{J}{ }_{(i)}\right)^{2}}$ is the distance from a discrete node $x_{i}$ to a sampling point $\mathrm{x}$ in the domain of support with radius $r_{w}$, and $\mathrm{c}$ is the dilation parameter. $c=\frac{r_{w}}{4}$ is used in computation.

The second part in Eq. 14 is in fact an interpolation of the residuals of the regression model $p^{T}(x) a$. Thus, all response data will be exactly predicted; is given as:

$$
Z(x)=r^{T}(x) \beta
$$

where $r^{T}$ is defined as follow:

$$
r^{T}(x)=\left\{R\left(x, x_{1}\right), \cdots, R\left(x, x_{n}\right)\right\}
$$

The parameters $\beta$ are defined as follows:

$$
\beta=R^{-1}(F-P a)
$$

\section{RESULT AND DISCUSSION}

\section{Optimization Results}

Two cases are proposed to optimize the wire coat hanger melt distributor. In the first case the manifold thickness distributions $H$ vary linearly according to the die circumferences $H(\alpha)$; in the second case $H$ vary linearly according to the die length $H(y)$. A study of the effects and interaction of the optimization variables shows that the interaction between the optimization variables is greater in case 2. This indicates that the nonlinearity of the function that has to be minimized, is greater compared to the case 1 .

The optimization example was carried out for LDPE $22 \mathrm{D} 780$ and using a flow rate of $120 \mathrm{~kg} / \mathrm{h}$. Using symmetry, only one half die is modeled. To show the improvement of the exit velocity distribution compared to the initial design, the convergence record at a given iteration step is assigned by the value of the objective function, and begin at iteration 0 with the objective function corresponding to the initial die geometry (a flat manifold of constant width $W_{0}=20$ ). To quantify the distributor performance, and to compare the numerical result to experimental measurement, a flow divider is used and attached to the crosshead instead of the wire coating tooling. This flow divider separates the flow

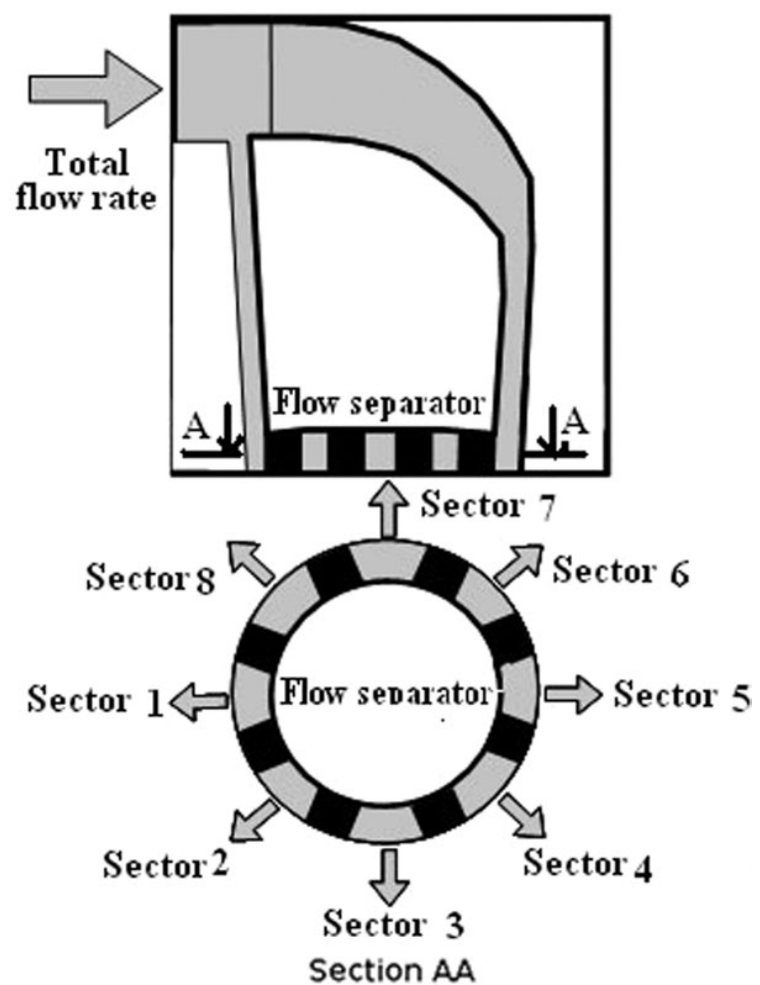

FIG. 5. Principle of flow separator for melt distribution measurement.

into eight runs, labeled sectors 1-8 (Fig. 5). Taking into account the symmetry, only the velocity distribution on the sector from 1 to 5 is presented.

A summary of the optimization results obtained for the two cases are referred in Table 2. According to this table, if the results are compared to the initial design, an improvement of the objective function of 87 and $86 \%$ for cases 1 and 2, respectively is obtained. However, the imposed limitation (constraint) of the pressure increases in the optimal die. It is noticed that the pressure complies with the constraint, and even decreased by 8 and $3 \%$ respectively for cases 1 and 2 .

The best solution suggested by the optimization algorithm in case 1 is $2.65 \%$ of total relative exit velocity variation, which corresponds to the set of parameter $W=$ $8.03 \mathrm{~mm}$, and $H(\alpha)=10.36$ at $\alpha=0$. In case 2 , the best solution is a relative exit velocity variation of $2.77 \%$. This solution corresponds to the variable $W=8 \mathrm{~mm}$ and a lower manifold thickness of $H(y)=7.23 \mathrm{~mm}$ at $y=0$.

The optimization convergence history of the objective and constraint function was shown in Fig. 6 for both results (cases 1 and 2). In the first optimization case, it is observed that the objective function decreases significantly by about $80 \%$ with the first iteration, then stabilizes and converges toward 0.134 . This corresponds to 28 F.E calculations. Concerning the second optimization case, the convergence is progressive. The optimum is then detected during the third iteration with the same reduction of the objective function as in case 1 . That implies a very fast convergence, with relatively weak exit velocity varia- 

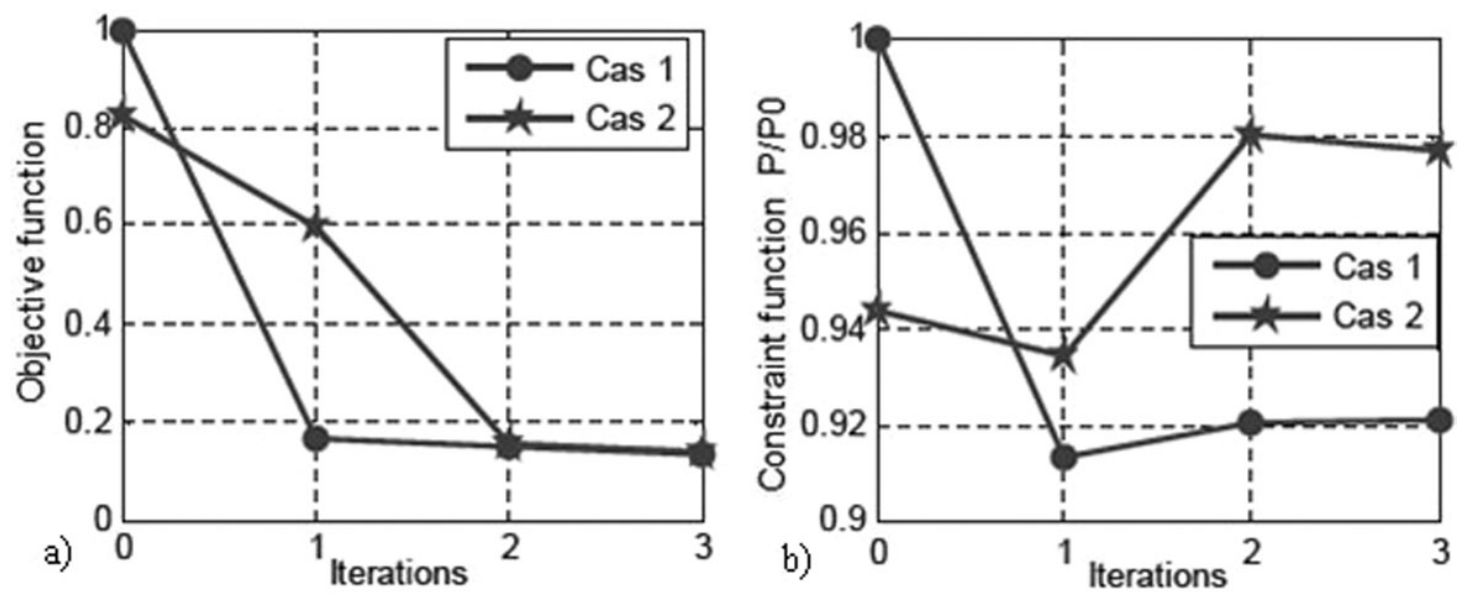

FIG. 6. Convergence history of the objective and constraint function during the optimization run.

tions, which represents a good improvement of the exit velocity distribution. The objective function is then reduced by 87 and $86 \%$ of its initial value, for respectively cases 1 and 2 .

Figure 7A, illustrates the dimensionless exit velocity distribution $(v(x) \bar{v}(x))$, for the initial and both optimal die design (cases 1 and 2). The both optimal results decrease the exit velocity variation compared to the initial design. On the other hand a slight irregularity of distribution is observed, for the two cases. This is due to the short manifold length (geometrical constraint). However, for a judicious choice of the optimal geometry to manufacture, it is desirable to observe the difference between the two distributions obtained.

For case 1, a weak exit velocity variation is observed on the end circumference of the die (sector 5). This irregularity can be improved using longer tools, whose effect will improve the final distribution of the flow exit.

For case 2, a minor variation of the exit velocity distribution is observed in the mid circumference of the half die (sector 3). The dimensionless velocity is lower by about $4 \%$ on sector 3 and a little higher on the ends (sectors 1 and 5). This defect is more difficult to improve. The design of the die gives a length of $95 \mathrm{~mm}$; the crosshead length before the flow separator is of 17.5. This gives a total flow length of $112.5 \mathrm{~mm}$. Figure 7B illustrates the velocity distribution for the real flow length (an additional length of $17.5 \mathrm{~mm}$ for the two optimal dies is added see Fig. 3). It is observed that the velocity distribution for the optimal die (case 1) is improved and the exit velocity variation balanced. On the other hand, in the second optimal die (e.g., 2), no improvement is obtained on the velocity distribution.

Effects of the Flow Rate and the Temperature on the Exit Velocity Distribution

The flow rate and melt temperature are very essential interest mainly for temperature-sensitive materials. The polymer temperature rises is influenced by thermal and rheological properties of extrudate, operating conditions of extrusion and geometry [23]. Smith [13] shows that the velocity distributions is affected by rheological properties and melt temperature. Carneiro and coworkers [16] have concluded that the most significant processing variable determining the mechanical properties of the extrusion profiles is the extrusion temperature.

A number of research articles on the effects of viscous heating on the melt-temperature have been published [2426]; Sombatsompop and Chaiwattanpipat [24] have studied the effect of flow rate on melt temperature measurement. The authors show that temperature of the melt changed continuously and the major parameters influenc-
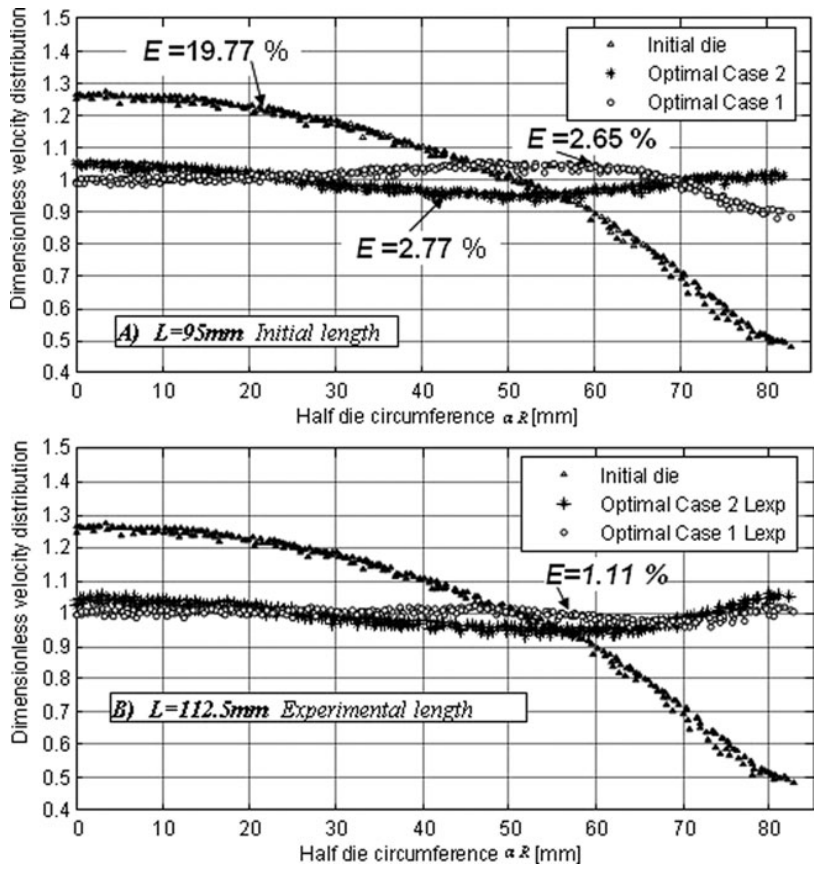

FIG. 7. Exit velocity (dimensionless) distribution in the initial and optimal dies. 


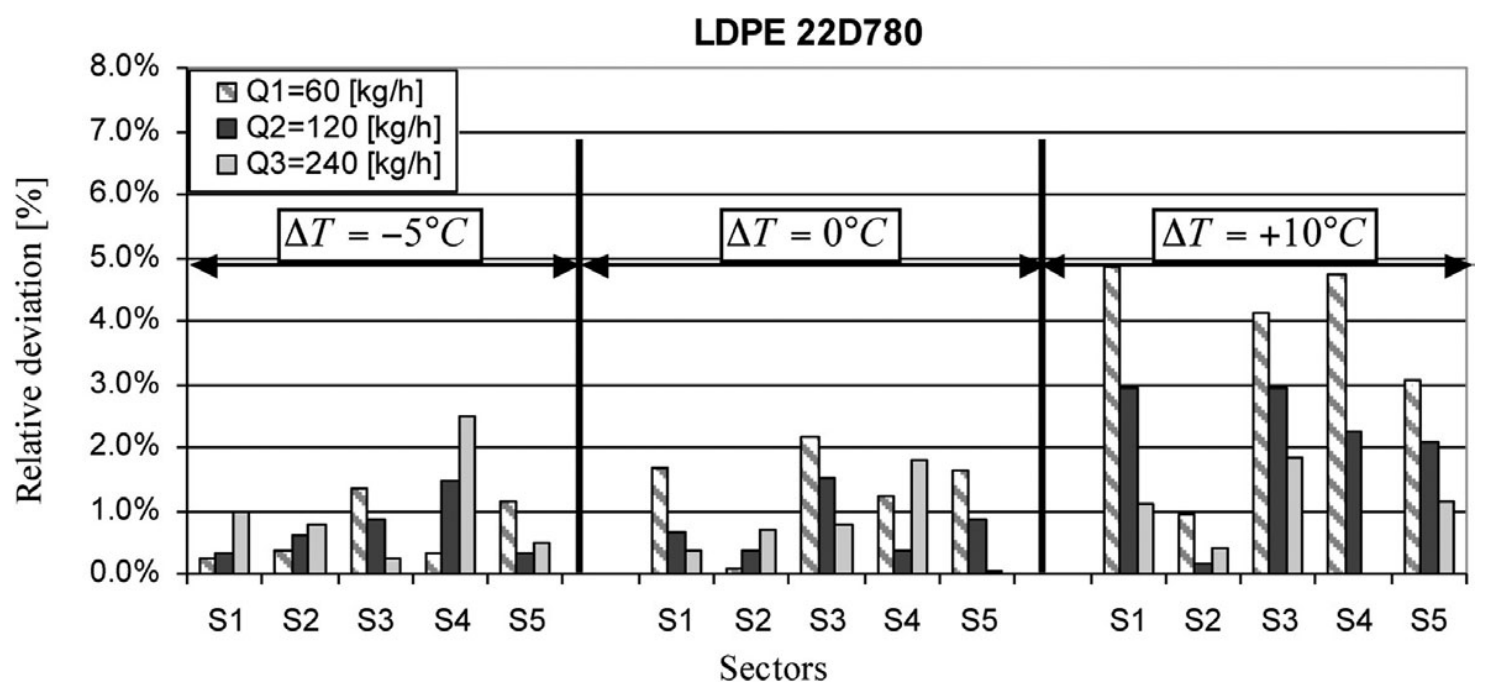

FIG. 8. Influence flow and temperature on the relative deviation of exit velocity distribution (LDPE 22D780).

ing the melt temperature were shear heating and heating conduction effects, residence time, and the flow.

The simulation results obtained by the optimal die for the LDPE 22D780 with various flows and various temperatures are summarized on Fig. 8. The important factors represented in the diagram are the influence of the flow rate $\left(Q_{i}\right)$ and the difference in temperature $\Delta T=T_{\mathrm{m}}-T_{\mathrm{f}}$ between the die wall temperature $\left(T_{\mathrm{f}}\right)$ and the melt temperature $\left(T_{\mathrm{m}}\right)$ on the exit velocity distribution results (relative deviation).

For a low flow $\left(Q_{1}=60[\mathrm{~kg} / \mathrm{h}]\right)$, a low influence of $\Delta T$ is observed. If the melt temperature $\left(T_{\mathrm{m}}\right)$ is hotter than the die wall temperature $\left(T_{\mathrm{f}}\right)$, the relative variation is about $5 \%$, whereas, when the melt temperature $\left(T_{\mathrm{m}}\right)$ is colder than the die wall $\left(T_{\mathrm{f}}\right)$, this relative deviation decreases become negligible (lower than $1.5 \%$ ).
When the flow rate increases $\left(Q_{2}=120[\mathrm{~kg} / \mathrm{h}]\right.$ and $Q_{3}$ $=240[\mathrm{~kg} / \mathrm{h}])$, the influence of $\Delta T$ on the relative velocity deviations decreases. For low flow rates, the increasing difference (in relative deviation) with $\Delta T$, can be explainable by the more important residence time and by the high temperature dependence of viscosity [26]. On the contrary, for high flow rates, the residence time is weaker. This would explain the smaller differences in the relative velocity deviations. On the one hand, the effect of temperature on the viscosity is more pronounced at low shear rates. The same result is reported by authors Del Coz Díaz et al. [27] particularly in the range of the zero shear viscosity.

The same study is made for another material. The results for Lupolene 1812D are represented on Fig. 9. For

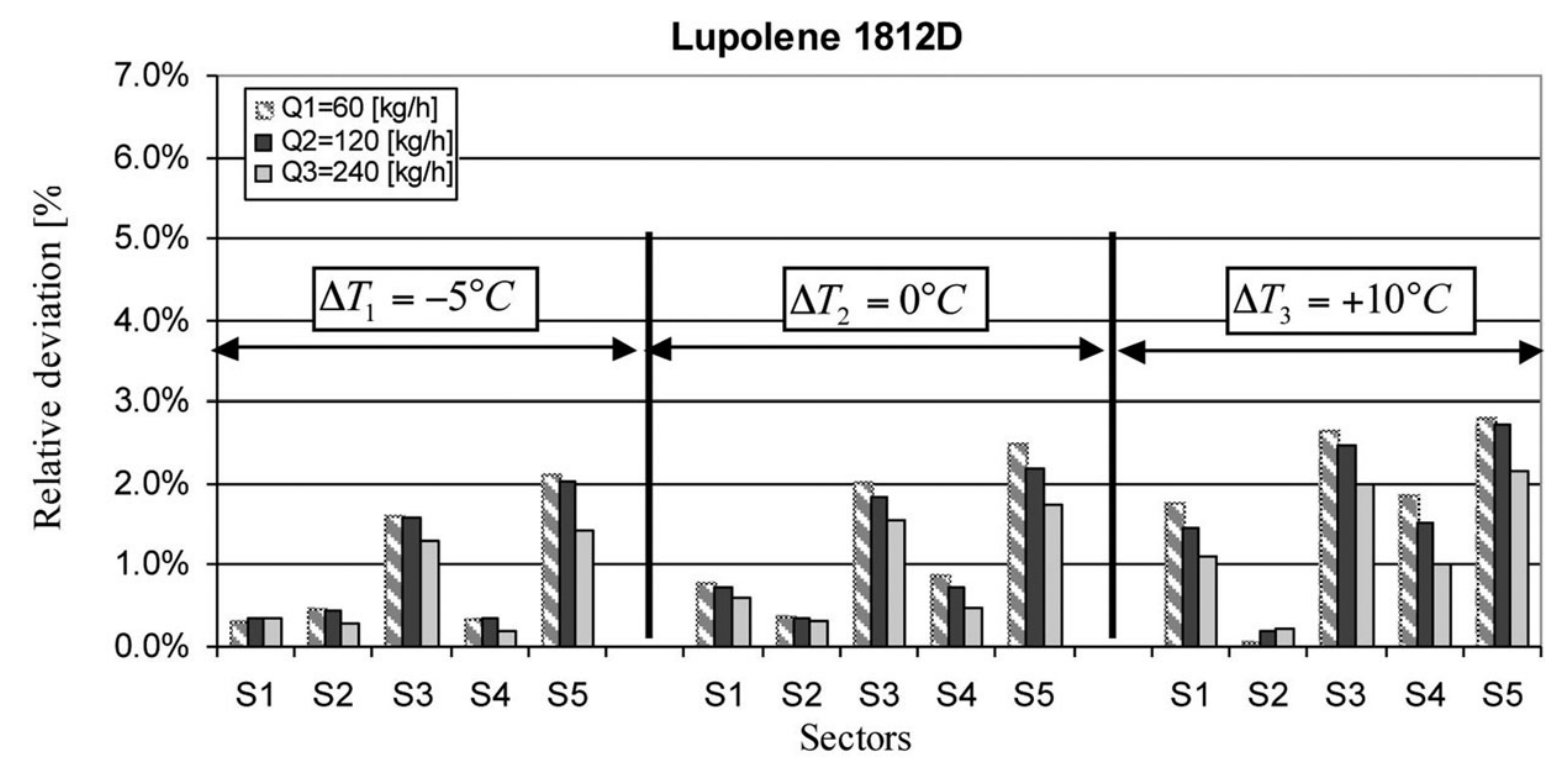

FIG. 9. Influence flow and temperature on the relative deviation of exit velocity distribution (Lupolen 1812D). 


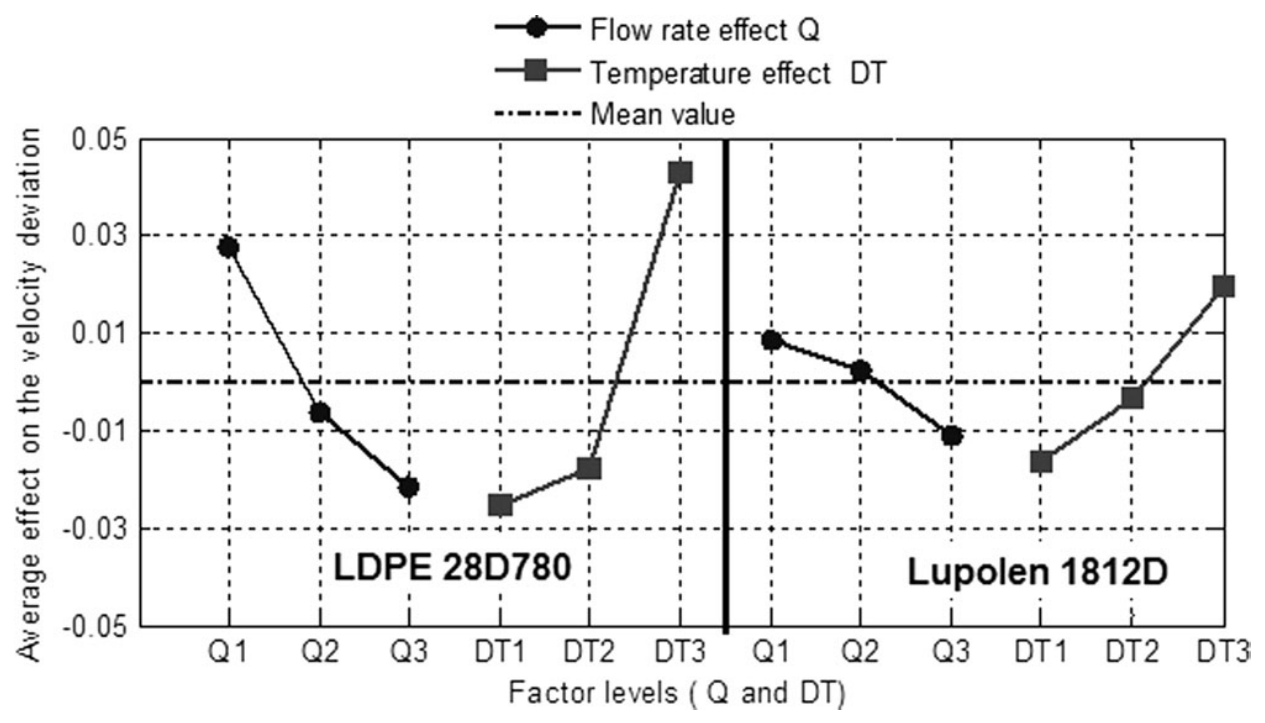

FIG. 10. Effect of the flow rate $Q$ and temperature $\Delta T$ levels on the exit velocity distribution for two materials.

a given flow, $\Delta T$ has a weak influence on the relative velocity deviation. Moreover for a given $\Delta T$ the relative deviation is similar whatever the flow rate.

For a melt distribution with $\Delta T=0^{\circ} \mathrm{C}$, it can be noticed that the maximum of the relative velocity deviations does not exceed $1.5 \%$. The difference between two polymers is minimal in term of velocity distribution. The objective function is clearly improved for the two polymers. Furthermore, for a melt distribution with $\Delta T=0$ the maximum of relative exit velocity variation is lower than $3 \%$.

Figure 10 illustrates the effect of differences $\Delta T$ between melt and die wall temperature also for flow rate $Q$, on the relative exit velocity deviation. It is noted that the effect of $\Delta T$ and the flow $Q$ are weaker for Lupolene 1812D, compared to the LDPE 22D780. This insensitivity is dependent on the smaller temperature dependence of the viscosity and its linear behavior according to the shear rate (Fig. 2). Also Figure 10 illustrate that, the relative variation is weaker (better distribution) with strong flow rate $\left(Q_{2}\right.$ and $\left.Q_{3}\right)$, and when the die wall temperature $\left(T_{\mathrm{f}}\right)$ is higher than melt temperature $\left(T_{\mathrm{m}}\right)$ i.e., $\Delta T<0$.

\section{Experimental Measurements and Validations}

The accuracy of the optimized wire coat hanger melt distributor is verified by manufacturing a prototype die based upon the optimal parameters found from simulation. The prototype die is shown in Fig. 11. The experimental test is composed of a single-screw extrusion machine, with screw diameter $45 \mathrm{~mm}$, equipped with a thermostatized extrusion head (distributor or crosshead) and with a flow separation device. The pressure losses were recorded using a fast system of pressure acquisition. Thermocouples were located on the head. The optimal die (case1) was produced by Maillefer extrusion. Two series of meas- urements were carried out for LDPE 28D780, with two different flows. Because of the measurement difficulties, the maximum flow rate that can be measured corresponds to $85.76[\mathrm{~kg} / \mathrm{h}]$. To quantify the distributor performance, the flow divider separates the flow into eight runs, labeled sector 1 to sector 8 (Figs. 5 and 11). The weight of the runs over a period of time directly indicates the distribution uniformity. The circumferential melt distribution is obtained by the repeated measurement of the mass flow rate at $36 \mathrm{~s}$ intervals for each partial flow. To improve the measurement accuracy for each series, the average value from three data sets is reported.

For reasons of symmetry, only the flow measurements on the sector from 1 to 5 is presented, sectors 2,3 , and 4 representing averages of corresponding sector pairs ( 2 and 8 ), (3 and 7), and (4 and 6). Table 3 presents the dimensionless velocities obtained from these output measurements.

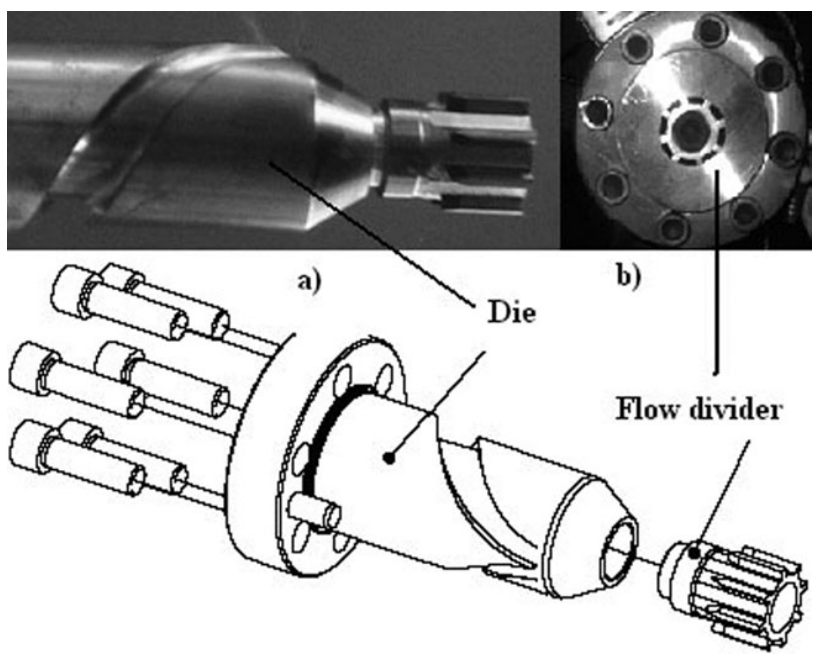

FIG. 11. Geometry of die (a) and flow divider (b). 
TABLE 3. Dimensionless exit velocity distribution at the different sectors (experimental data).

\begin{tabular}{lcc}
\hline & \multicolumn{2}{c}{ Data } \\
& 1 & \\
\cline { 2 - 3 } & $N(\mathrm{rpm})=150$ & 2 \\
\cline { 2 - 3 } & $\begin{array}{cc}\text { Dimensionless velocity } \\
\text { distribution } \bar{v}_{\text {mes }}^{a}\end{array}$ & $\begin{array}{c}\text { Dimensionless velocity } \\
\text { distribution } \bar{v}_{\text {mes }}^{a}\end{array}$ \\
\hline$S_{1}$ & 1.037 & 1.047 \\
$S_{2}$ & 0.989 & 0.984 \\
$S_{3}$ & 0.983 & 0.978 \\
$S_{4}$ & 0.979 & 0.975 \\
$S_{5}$ & 1.01 & 1.016 \\
Average & 1 & 1 \\
$E_{g}^{s}$ & 9.62 & 12.57 \\
\hline
\end{tabular}

The results of numerical simulation $\left(\mathrm{REM}_{3} \mathrm{D}^{\circledR}\right)$ are obtained for the same flow rates as measured on the optimal die. An example of the simulation result is illustrated Fig. 12. This figure presents velocity distributions and pressures in the optimal geometry for flow $\left(Q_{1}=63.8 / 2\right.$ $[\mathrm{kg} / \mathrm{h}])$. The pressures drop in this die for this flow is equal to $23.53 \mathrm{MPa}$. The calculated velocity distribution at the die exit (illustrated by vectors) shows a good homogeneity.

The simulated outflow results (Fig. 12) are compared with outlets measured on the actual extrusion die. Figure 13 illustrates for two flow rates the relative mean velocity deviation for the calculated and experimental measurements for two flows. The result of the relative mean velocity deviation is presented for each sector at the die exit. It can be noted that the experimental measurements carried out for the optimal geometry indicate a good exit velocity distribution, with relative deviations lower than

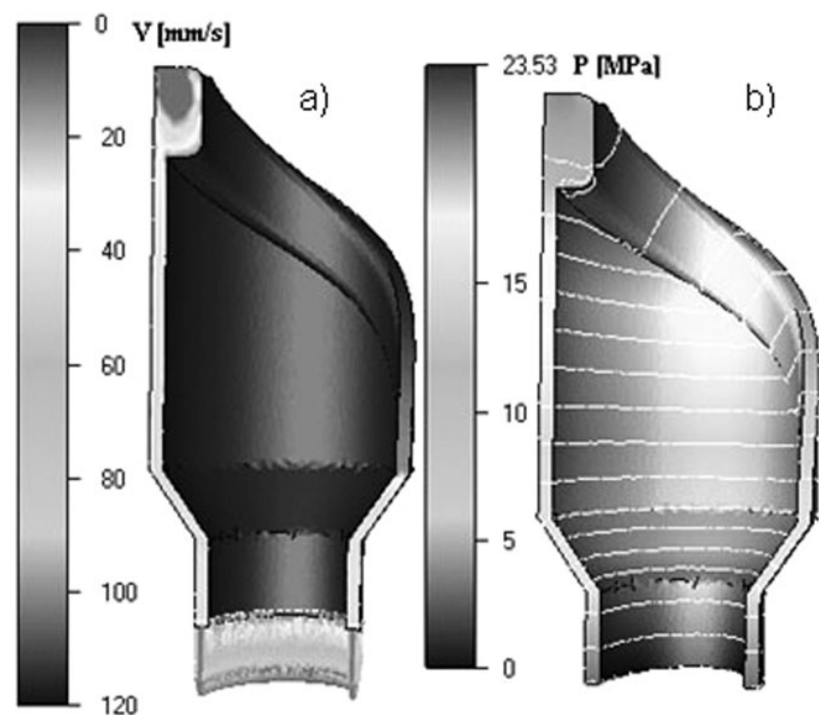

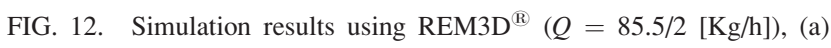
velocity distributions and (b) pressure.

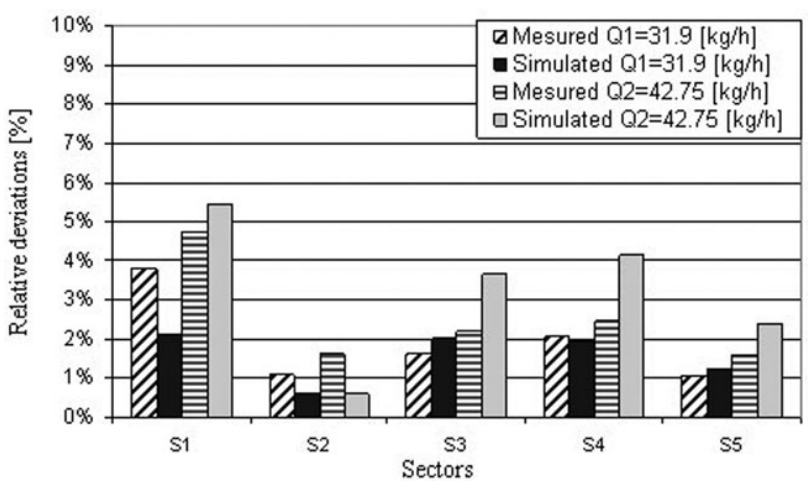

FIG. 13. Relative deviation of the average velocities in the different sectors (Experimental data and numerical calculations).

$5 \%$. The numerical simulation (REM3D ${ }^{\circledR}$ calculation) indicates the same order of magnitude. Note that the maximum difference between the measured and calculated velocity deviations is about a $1.5 \%$.Considering the precision of the measurements, this discrepancy is small.

The optimal die design was optimized for a high flow rate $\left(Q_{1}=120[\mathrm{~kg} / \mathrm{h}]\right)$. It was showed in Fig. 10 that when the flow increases (respectively decreases) the distribution improves (respectively is degraded). However, for low flow rates, a good velocity distribution is obtained (experimental measurements and calculation) (Fig. 13). This implies that the adopted optimization procedure makes it possible to obtain a geometry giving a good velocity distribution for a wide flow rate range. Experimental measurements were carried out on the optimal die for various polymers and with various flow rates (Table 4). Three polymers were selected to compare the sensitivity of the velocity distribution, for a large material range.

The experimental flow distribution of the optimal die design for a range of different material and for two flow rates are shown in Fig. 14. This figure illustrates the mean velocity distribution in dimensionless form. For reasons of symmetry the sectors from 1 to 5 are presented. Thus, it can be noticed that the optimal die gives better velocity homogeneity for three polymers, a LLDPE, a PVC and a

TABLE 4. Experimental flow measurement in the optimal die for different polymer.

\begin{tabular}{lcccc}
\hline \multicolumn{1}{c}{ Material } & $\begin{array}{c}\text { LLDE LLN } \\
1004 \mathrm{YB}\end{array}$ & $\begin{array}{c}\text { PVC FKS } \\
910 \mathrm{R}\end{array}$ & \multicolumn{2}{c}{ LDPE 28D780 } \\
\hline $\mathrm{N} \mathrm{tr} / \mathrm{min}$ & 200 & 150 & 150 & 200 \\
$T_{\mathrm{f}}\left[{ }^{\circ} \mathrm{C}\right]$ & 185 & 171 & 187 & 190 \\
$Q_{\mathrm{S} 1}[\mathrm{~kg} / \mathrm{h}]$ & 9.72 & 12.47 & 8.33 & 11.31 \\
$Q_{\mathrm{S} 2}[\mathrm{~kg} / \mathrm{h}]$ & 9.88 & 12.74 & 7.94 & 10.64 \\
$Q_{\mathrm{S} 3}[\mathrm{~kg} / \mathrm{h}]$ & 9.99 & 12.97 & 7.87 & 10.53 \\
$Q_{\mathrm{S} 4}[\mathrm{~kg} / \mathrm{h}]$ & 10.06 & 13.01 & 7.85 & 10.52 \\
$Q_{\mathrm{S} 5}[\mathrm{~kg} / \mathrm{h}]$ & 9.65 & 12.10 & 8.11 & 10.97 \\
$Q_{\mathrm{S} 6}[\mathrm{~kg} / \mathrm{h}]$ & 10.06 & 12.91 & 7.87 & 10.56 \\
$Q_{\mathrm{S} 7}[\mathrm{~kg} / \mathrm{h}]$ & 9.95 & 12.99 & 7.93 & 10.60 \\
$Q_{\mathrm{S} 8}[\mathrm{~kg} / \mathrm{h}]$ & 9.88 & 12.74 & 7.94 & 10.61 \\
$Q_{\text {total }}[\mathrm{kg} / \mathrm{h}]$ & 79.2 & 101.92 & 63.84 & 85.76 \\
\hline
\end{tabular}




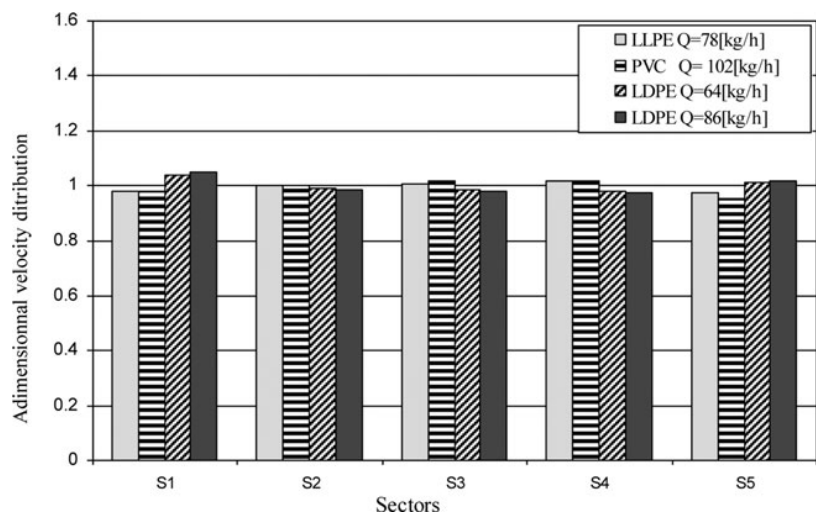

FIG. 14. Exit flow distribution in the different sectors of the optimal die for a range of different polymer (Experimental data).

LDPE for two different flows (LDPE). This implies that the optimal die makes it possible to obtain a good velocity distribution for a different polymer range and a wide flow range (interval).

\section{CONCLUSION}

In this article, an industrial application was presented. The purpose of this work was to find the optimal wire coat hanger die design, to obtain a homogenous exit velocity distribution for a wide material range and multiple operating conditions. On the basis of a circumference $(R . \pi)$, a slit die length $H$, and geometrical limitations due to die-manufacturing requirements, an initial design of a wire coat hanger die is obtained using an analytical model. This design gave us a bad distribution of velocities on the outlet side of the die (due to the three-dimensional effects). Nevertheless this die induces a low sensitivity of the exit velocity distribution for various polymers. This characteristic enabled us to optimize the geometry of the die to obtain a homogenous distribution for a range of polymers.

An optimization strategy based on Kriging method and a nonlinear unconstrained optimization algorithm (SQP) has enabled us to determine the set of geometrical variables leading to an optimal solution. The results show an improvement of the velocity distribution, for two polymers which have a different rheological behavior. Then, using the Taguchi method, the effects of the operating conditions (flow rate and temperature) on the improvement of the velocity distribution, are analyzed and compared, for two different polymers.

The optimal die was manufactured and an experimental comparison made it possible to validate the overall simulation procedure and the robustness of the optimization strategy. The experimental measurements and the flow dynamic results of the numerical calculations were in excellent agreement, within the experimental data. The experimental results and simulation show that the optimal die makes it possible to ensure a good velocity distribu- tion, for various polymers and have a minor sensitivity to processing conditions.

This work showed the potential of the optimization method. Its robustness should be verified in the case of other kind of polymer extrusion geometries (flat dies, spiral mandrel dies). And even other type of manufacturing processes may take an advantage of it. Future research will involve including in the optimization scheme the presence of uncertainties. The strategy combines the actual optimization technique with a perturbation method for the quantification of uncertainties associated with operating conditions and or uncertain material properties.

\section{ACKNOWLEDGMENTS}

The support of Maillefer SA is gratefully acknowledged.

\section{REFERENCES}

1. S.J. Bates, J. Sienz, J.F.T. Pittman, and D.S. Langley, Polym. Eng. Sci., 43, 1500 (2003).

2. N. Lebaal, F. Schmidt, and S. Puissant, Finite Element Anal. Des., 45, 333 (2009).

3. N. Lebaal, S. Puissant, and F. Schmidt, Int. J. Mat. Form., 38, 307 (2010).

4. C. Chen, P. Jen, and F.S. Lai, Polym. Eng. Sci., 37, 188 (1997).

5. Y. Wang, Polym. Eng. Sci., 31, 204 (1991).

6. B. Younes, A. Fotheringham, and H.M. El-Dessouky, J. Appl. Polym. Sci., 118, 1270 (2010).

7. B. Younes and A. Fotheringham, J. Appl. Polym. Sci., 119, 1896 (2011).

8. O.S. Carneiro, J.C. Viana, and J.M. Nóbrega, Plast Rubber Compos., 35, 173 (2006).

9. A.F. Bastani, T. Aukrust, and S. Brandal, J. Mat. Process Tech., 211, 650 (2011).

10. J. Sienz, S.J. Bates, and J.F.T. Pittman, Finite Element Anal. Des., 42, 430 (2006).

11. H.H. Winter and H.G. Fritz, Polym. Eng. Sci., 26, 543 (1986).

12. N. Lebaal, F.M. Schmidt, S. Puissant, and D. Schlaefli, Polym. Eng. Sci., 49, 3432 (2009).

13. D.E. Smith, SPE ANTEC Technical Papers, Nashville, TN, USA, May 4-8 (2003).

14. A.R. Shahreza, A.H. Behravesh, M.B. Jooybari, and E. Soury, Polym. Eng. Sci., 50, 2417 (2010).

15. J. Sienz, A. Goublomme, and M. Luege, Comput. Struct., 88, 610 (2010).

16. J.M. Nóbrega, O.S. Carneiro, F.T. Pinho, and P.J. Oliveira, Int. Polym. Process., 19, 225 (2004)

17. Y. Mu, GQ. Zhao, XH. Wu, and CH. Zhang, Int. J. Adv. Manuf Tech., 50, 517 (2010).

18. Z. Wei, Y.X. Feng, J.R. Tan, J.L. Wang, and Z.K. Li, Int. J. Adv. Manuf Tech., 41, 242 (2009). 
19. D. Schläfli, Int. Polym. Process., 10, 195 (1995).

20. D.C. Montgomery, Design, and Analysis of Experiments, Wiley, USA, (2005).

21. N. Lebaal, M. Nouari, and A. Ginting, Appl. Soft Comput., 11, 5110 (2011).

22. H. Liu and S. Maghsoodloo, Appl. Soft Comput., 11, 3451 (2011).

23. I. Sbarski, E. Kosior, and S.N. Bhattacharya, Int. Polym. Process., 12, 341 (1997).
24. N. Sombatsompop and W. Chaiwattanpipat, Adv. Polym. Technol., 19, 79 (2000)

25. N. Sombatsompop and W. Chaiwattanpipat, Polym. Test., 19, 713 (2000)

26. N. Sombatsompop, W. Chaiwattanpipat, and M. Panapoy, Mater. Res. Innovat., 3, 271 (2000).

27. J.J. del Coz Díaz, P.J. García Nieto, A. Bello García, J. Guerrero Muñoz, and J. Ordieres Meré, J. Non-Cryst. Solids, 354, 5334 (2008). 